\title{
Isolation of a chromosomally engineered durum wheat line carrying the common wheat Glu-DId allele
}

\author{
F Vitellozzi, M Ciaffi, L Dominici, C Ceoloni* \\ Department of Agrobiology and Agrochemistry, University of Tuscia, 01100 Viterbo, Italy
}

(Received 29 July 1997; accepted 30 September 1997)

\begin{abstract}
Summary - A 1DL chromosomal segment, containing the Glu-DId allele coding for the ' $5+10^{\prime}$ HMW glutenin subunits, has been transferred into the $1 \mathrm{AL}$ arm of a tetraploid derivative by means of $p h l c$ induced homoeologous recombination in backcross progeny derived from an initial common wheat $x$ durum wheat cross. The involvement of $1 \mathrm{AL}$ in the exchange, which could not be directly proved by the protein assay because of the null condition at the GluAl locus in all durum wheat parents used, was unequivocally demonstrated using the D genome specific, highly repeated DNA sequence pAs1 as probe in fluorescence in situ hybridization (FISH) experiments. The Glu-Dld tetraploid carrier in fact exhibits a normal $1 \mathrm{AS}$ and a recombined $1 \mathrm{AL}$, with a distal segment of clear $1 \mathrm{DL}$ origin. The difference between the FISH patterns of recombined and normal 1 AL was used to discriminate homozygous from heterozygous $G l u-D 1 d$ carriers already in F2 populations, in which the recombined chromosome appeared to be transmitted normally through both germlines. Preliminary tests also show no reduction in fertility due to either one or two doses of the engineered chromosome, whose impact on various pasta and bread making quality parameters will be assessed. (@ Inra/Elsevier)
\end{abstract}

durum wheat / common wheat / chromosome engineering / 1D storage proteins

Résumé - Isolement par manipulation chromosomique d'une lignée de blé dur contenant l'allèle Glu-DId du blé tendre. Au moyen de la recombinaison homéologue induite par la mutation phlc dans la descendance issue du rétrocroisement d'un blé tendre par un blé dur, un segment du chromosome 1DL a été transféré dans le bras $1 \mathrm{AL}$ d'un dérivé tétraploïde. Le segment contient l'allèle Glu-Dl codant pour les sous-unités des gluténines de poids moléculaire élevé (HMW) « 5+ 10 ». L'implication dans l'échange du chromosome 1AL, qu'il n'a pas été possible de démontrer par l'essai protéique à cause de la condition nulle de l'allèle au locus Glu-A1 de tous les blés durs employés, a été démontrée par l'hybridation in situ en fluorescence (FISH) avec la séquence répétée pAs1 spécifique du génome D. En effet, la lignée tétraploïde contenant l'allèle $G l u$-Dld montre un 1 AS normal et un 1 AL recombiné, avec un segment distal qui provient clairement du chromosome 1DL. Les différents profils d'hybridation des chromosomes $1 \mathrm{AL}$ normal et recombiné ont été utilisés pour distinguer les homozygotes Glu-Dld des hétérozygotes dans les populations F2, dans lesquelles nous avons observé une transmission normale du chromosome recombiné par les voies mâle et femelle. Des essais préliminaires n'ont indiqué aucune réduction de la fertilité tant des homozygotes que des hétérozygotes pour le chromosome recombiné. (@ Inra/Elsevier)

blé dur / blé tendre / manipulation chromosomique / protéines de réserve du 10

Article communicated by Nicolás Jouve (Madrid)

* Correspondence and reprints

Tel: (39) 761 357202; fax: 761 357242; e-mail: ceoloni@unitus.it 


\section{INTRODUCTION}

Durum wheat, $T$ durum $(2 \mathrm{n}=4 \mathrm{x}=28)$, a crop of considerable economic importance for countries of the Mediterranean Basin, but also well adapted to more extreme environments (Bozzini, 1988), is a species less amenable to chromosomal manipulations than common wheat, Triticum aestivum $\mathrm{L}$ $(2 n=6 x=42)$. The reduced tolerance to chromosomal imbalances inherent in the tetraploid condition, has substantially limited the number of successful alien introgressions in the former species with respect to the latter (see, eg, Gale and Miller, 1987; Ceoloni et al, 1996).

Nonetheless, various alien transfer projects have recently been carried out (Ceoloni et al, 1996) with the aim of widening the genetic base of cultivated durum wheat germplasm. One of the main goals is the improvement of the technological properties of durum wheat semolina.

Bread making quality of Triticum aestivum and pasta making quality of $T$ durum are known to be largely influenced by both the quantity and the quality of the main gluten proteins, gliadins and glutenins, which are controlled by genes on chromosomes of homoeologous groups 1 and 6 (Payne et al, 1984). Among these, Glu-3 genes, located on the short arm of group-1 chromosomes and coding for low molecular weight (LMW) glutenin subunits, appear to contribute significantly to durum wheat gluten viscoelasticity, an important factor in pasta cooking quality (Autran and Feillet, 1985; Turchetta et al, 1995). In this respect, gliadins encoded by $G l i-1$ genes, which are used as genetic markers for the closely linked Glu-3 genes, do not seem to have a direct functional role (Pogna et al, 1990).

On the other hand, baking quality of common wheat appears to be mainly associated with high molecular weight (HMW) glutenin subunits encoded by Glu-1 genes (long arm of group-1 chromosomes) and, to a lesser extent, with Glu-3 LMW-glutenins (Gupta et al, 1994). Rogers et al (1990), using Chinese Spring group 1 and 6 aneuploid lines, showed that the storage protein genes controlled by chromosome 1D have a major impact on bread making properties. In particular, a dramatic reduction of common wheat dough rheological properties was observed in null genotypes at the Glu-Dl locus (Lawrence et al, 1988; Lafiandra et al, 1993). This observation is in agreement with other ones indicating that the GluDI locus accounts for the largest part of the total variation in gluten quality, with the Glu-DId allele (' $5+10^{\prime}$ subunits) determining the most significant improvement (Payne et al, 1987; Benedetteli et al, 1992).

In durum wheat, the poor correlation observed between variation in HMW glutenin subunits and technological quality has been attributed not only to the intrinsic genomic difference with respect to common wheat (Josephides et al, 1987), but also to a limited genetic variability of Glu- $I$ genes in the existing durum germplasm, within which lowscore alleles are mostly present (Branlard et al, 1989; Turchetta et al, 1995). Recently, analysis of the entire set of Langdon D genome disomic substitution lines clearly indicated the major effect of chromosome 1D on gluten strength, as measured by SDS-sedimentation and mixograph texts (Liu et al, 1995). This effect was associated with an increase in the relative amount of glutenin, particularly the highly aggregated fraction, and a decrease in the relative gliadin content.

This body of evidence prompted to the transfer, through phl mediated chromosome engineering, of 1D storage protein genes into cultivated relatives, including $T$ durum and triticale, in which quality attributes typical of T aestivum are lacking or poorly expressed. 1DL chromosomal segments containing the $G l u-D 1 d$ allele were transferred into chromosome 1R (Lukaszewski and Curtis, 1992) and 1A (Lukaszewski and Curtis, 1994) of hexaploid triticale by means of induced homoeologous recombination. We carried out a similar work, aiming to transfer both the Glu-Dld encoded HMW and the Glu-D3 LMW glutenin subunits into durum wheat (Ceoloni et al, 1992, 1995, 1996). As described previously (Ceoloni et al, 1996), whereas isolation of $2 \mathrm{n}=28$ potentially desirable types, with Glu-D1 and Gli-DI/Glu-D3 dissociated protein markers, occurred relatively early during the transfer work, their maintenance was prevented in several instances, most probably due to chromosomal instabilities caused by the prolonged $p h l / p h l$ condition. This condition was in fact necessary to promote the desired 1D-1A or 1D-1B homoeologous exchanges. However, stable

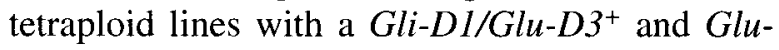
$D I^{-}$protein phenotype and a clear recombinational origin (Ceoloni et al, 1996), could be eventually isolated as the first outcome of such a transfer project.

This paper describes the isolation and characterization through both protein analyses and fluorescence in situ hybridization (FISH) of a stable tetraploid recombinant line containing a common wheat 1DL segment with the Glu-DId allele. 


\section{MATERIALS AND METHODS}

Details of the materials and transfer procedure employed were previously given (Ceoloni et al, 1995). In the crossing scheme, the Cimmyt variety Torim 73, possessing the Glu-Dld allele, was initially crossed with Chinese Spring (CS) phlb mutant (Glu-Dla allele, ' $2+12$ ' subunits) and their F1 crossed and backcrossed several times to the phlc mutant of the durum cv. Cappelli (Giorgi 1978). This enabled us to obtain the necessary $p h l$ homozygous recessive condition for homoeologous recombination to occur and to bring the chromosome number to the tetraploid $2 n=28$.

In segregating progeny, whose somatic chromosome numbers were established with conventional staining techniques, one-dimensional (1-D) electrophoretic separation of gliadins, extracted with $1.5 \mathrm{M}$ dimethylformamide, was performed according to Khan et al (1985). HMW and LMW glutenin subunits were analysed using the one step 1-D SDS-PAGE procedure of Ciaffi et al (1993).

FISH was applied onto pretreated root-tip chromosome spreads using the pAs1 clone, isolated from Ae squarrosa (Rayburn and Gill, 1986), as probe. This probe contains a highly repeated sequence, which in common wheat hybridizes mainly with the D-genome chromosomes, each characterized by several diagnostic landmarks. A few and generally fainter sites are also detected on some A and B genome chromosomes (Mukai et al, 1993; this paper, see Results). In situ hybridization was performed following the experimental procedures described in Cuadrado et al (1997), except for probe labeling, which was carried out by nick-translation with biotin-14-dATP (BioNick Labeling System, Gibco BRL), and probe detection, which was performed using avidin conjugated with the red fluorescent $\mathrm{Cy} 3$ dye (Biological Detection Systems).

\section{RESULTS}

\section{Isolation of Glu-DI+ and Gli-DI/Glu-D3- plants}

Plants possessing $G l u-D l$ encoded proteins and lacking Gli-Dl/Glu-D3 protein subunits had been selected earlier through electrophoretic analyses in the $\mathrm{BC} 2$ progeny of (Torim $73 \times$ Chinese Spring phlb mutant) F1s crossed with Cappelli phlc, but all such plants died precociously (Ceoloni et al, 1996). However, genotypes with this same protein composition were later recovered in the $\mathrm{BC} 4$ progeny from the cross to Cappelli phlc of a BC3 plant possessing a $2 \mathrm{n}=32$ chromosome number and exhibiting both the Gli-DI/Glu-D3 (1DS) as well as the $G l u-D l^{\prime} 5+10^{\prime}$ (1DL) protein subunits. Out of a progeny of 21 individuals, two Glu-D1 ' $5+10^{\prime}$ carriers $\left(G l i-D l / G l u-D 3^{-}\right)$, having $2 \mathrm{n}=30$, were selected (fig 1). One of these died in early stages of development, whereas the other one reached maturity and later proved to be an homoeologous exchange product (see later). Assuming that both such plants had a recombinational origin, a total recombination frequency of $20 \%$ can be estimated.

From selfing of the surviving plant a few seeds were obtained, of which one developed into a regularly growing plant (designated E11), still having a $2 n=30$. This plant was evidently homozygous for the 1DL exchange involving the Glu-Dl locus, as indicated by the electrophoretic profiles of its $2 \mathrm{n}=28$ derivatives from crosses with $P h I$ durum wheats, all exhibiting the ' $5+10$ ' HMW glutenin subunits of the putative recombinant parent (fig 2).

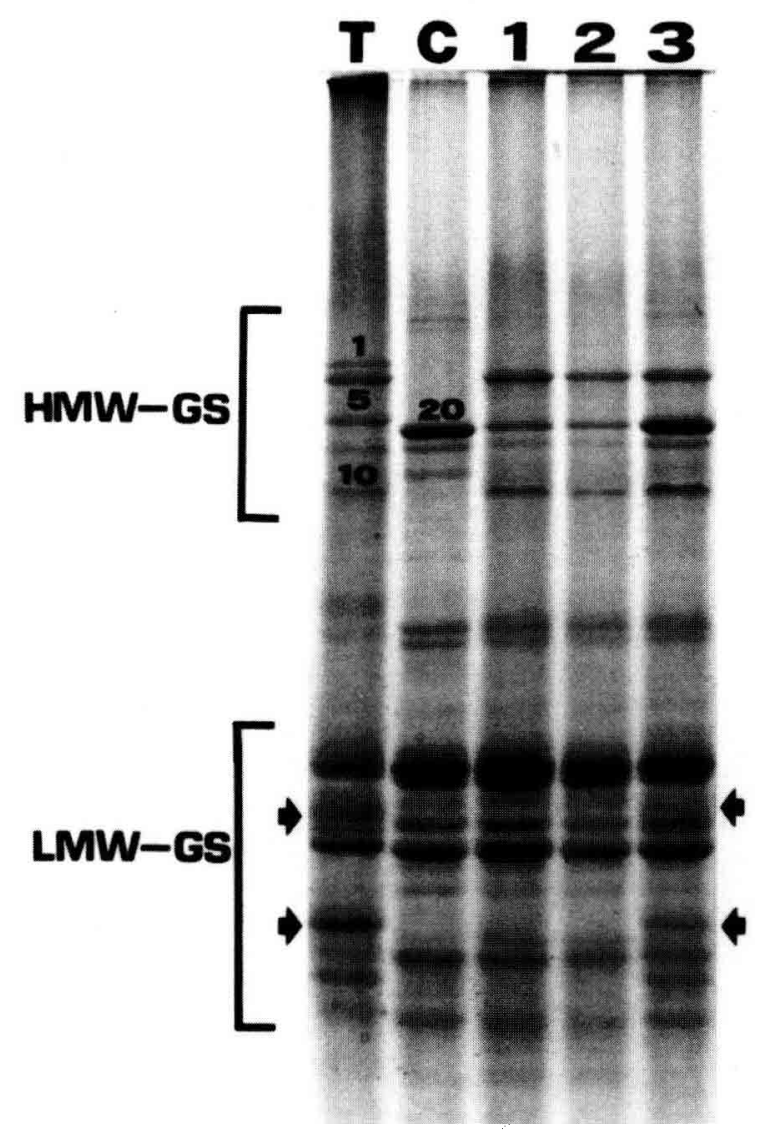

Fig 1. SDS-PAGE separation of glutenins extracted from plants isolated in the $\mathrm{BC} 4$ progeny from the cross to Cappelli phlc of (Torim $73 \times$ Chinese Spring phlb mutant) F1 and from their controls. Arrows indicate the main Glu-D3 LMW glutenin subunits, present in Torim 73 (T) and in a Glu$D I^{+} / G l u-D 3^{+}$segregant (lane 3) but absent in two Glu$\mathrm{DI}^{+} / \mathrm{G} / \mathrm{u}-\mathrm{D} 3^{-}$segregants (lanes 1 and 2). Numbers indicate HMW glutenin subunits controlled by the Glu-Al (subunit '1'), Glu-Dl ('5+10') and Glu-Bl ('20') loci in Torim 73 (T) and Cappelli (C). 


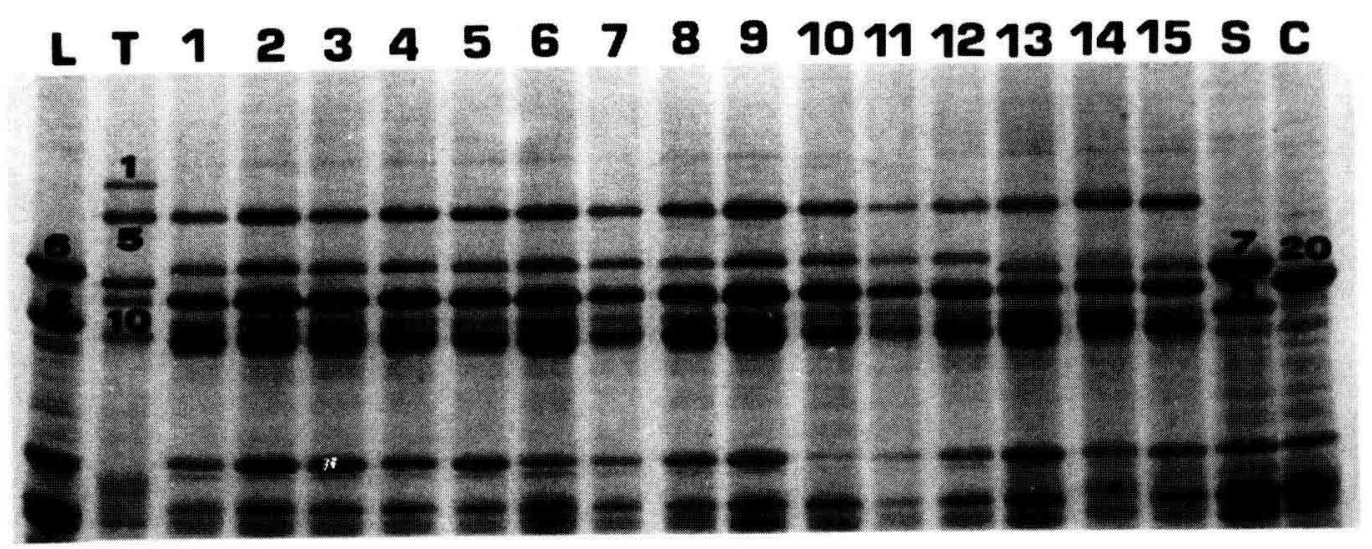

Fig 2. HMW glutenin subunits present in plants segregating from the cross between the ' $5+10^{\prime}$ E11 recombinant line and durum wheat cvs. Langdon (lanes 1-12) and Simeto (lanes 13-15). Numbers indicate subunits controlled by the Glu-AI (subunit '1'), Glu$D I\left({ }^{\prime} 5+10^{\prime}\right)$ and Glu-BI ('6+8', '7+8', '20') loci in Torim $73(\mathrm{~T})$, Langdon (L), Simeto (S) and Cappelli (C).

\section{Characterization of the 1DL exchange}

Regarding the durum wheat chromosome partecipating in the E11 1DL exchange, the involvement of $1 \mathrm{BL}$ could be excluded already on the basis of protein assay. In fact, all plants derived from crossing E11 with various $P h l$ durum wheats exhibited the 1B HMW glutenin subunit ' 20 ' of line E11 (see lane 1 in fig 1), together with Glu-BI glutenin subunits of the different durum wheat parents (fig 2).

Direct proof of the involvement of chromosome 1A could not be provided by the protein assay, since all durum wheat parents used carried a null $G l u-A 1$ allele. Moreover, the same assay did not allow discrimination between a 1 AS.1DL centricbreak-fusion and a 1AL-1DL homoeologous recombination as the causative event of the E11 1DL exchange.

The application of FISH, using the D genome specific, highly repeated DNA sequence pAs1 as probe (Rayburn and Gill, 1986), provided unequivocal evidence of a homoeologous exchange having occurred between $1 \mathrm{DL}$ and $1 \mathrm{AL}$ and allowed, at the same time, estimation of the size of the transferred segment. pAs1 in fact shows characteristic hybridization sites in the distal portions of $1 \mathrm{DL}$ and $1 \mathrm{DS}$, no site on $1 \mathrm{AL}$ and a minor, distal one on $1 \mathrm{AS}$ (see fig $3 \mathrm{~A}, \mathrm{~B}$ and Mukai et al, 1993).

In our FISH experiments a higher resolution than previously attained (Mukai et al, 1993) allowed detection of two closely positioned sites on the distal third of the 1DL arm, consisting of a prominent and more proximal one, immediately followed by a minor and more distal one (fig $3 \mathrm{~A}$ ).
Interestingly, line E11 as well as its ' $5+10$ ' derivatives exhibited a normal $1 \mathrm{AS}$ and a clearly recombined $1 \mathrm{AL}$ arm. In the latter, a minor pAs1 site is present whose intensity and position are of clear 1DL origin (fig 3C). A $1 \mathrm{AL} / 1 \mathrm{DL}$ exchange thus evidently occurred within the euchromatin separating the two pAs1 bands on 1DL and, as a result of this, a distal 1DL segment, representing about $25 \%$ of the recombined arm (fig $3 \mathrm{C}$ ), replaced a homoeologous $1 \mathrm{AL}$ portion.

The difference in FISH patterns of recombined and normal $1 \mathrm{AL}$ provided a useful system to discriminate between homozygous and heterozygous Glu-Dld carriers in segregating populations, which was not possible through SDS-PAGE owing to the null condition at the Glu-AI locus of the durum wheat parents. In fact, to evaluate the transmission ability of the recombined chromosome, BC1 (not shown) and F2 progeny (table I) from crosses with normal durum wheats, were first screened using the protein assay. In both cases no significant deviation from a normal ratio was observed (table I), which was already indicative of no competitive disadvantage suffered by gametes bearing the recombinant chromosome instead of a normal 1A chromosome. This result was further substantiated by FISH analysis of a sample of $\mathrm{Glu}^{-}$ $\mathrm{DI}^{+} \mathrm{F} 2$ segregants, which showed a perfect fit to a 1:2 ratio between homozygotes and heterozygotes for the $1 \mathrm{AL} / 1 \mathrm{DL}$ exchange (table I).

Not only the engineered chromosome has no negative effect on gametic behaviour, but also there is no apparent reduction in fertility of plants bearing it in either one or two doses: heterozygous as well as homozygous $G l u-D I^{+}$individuals in fact showed a similar seed set $(1.89 \pm 0.15$ and 

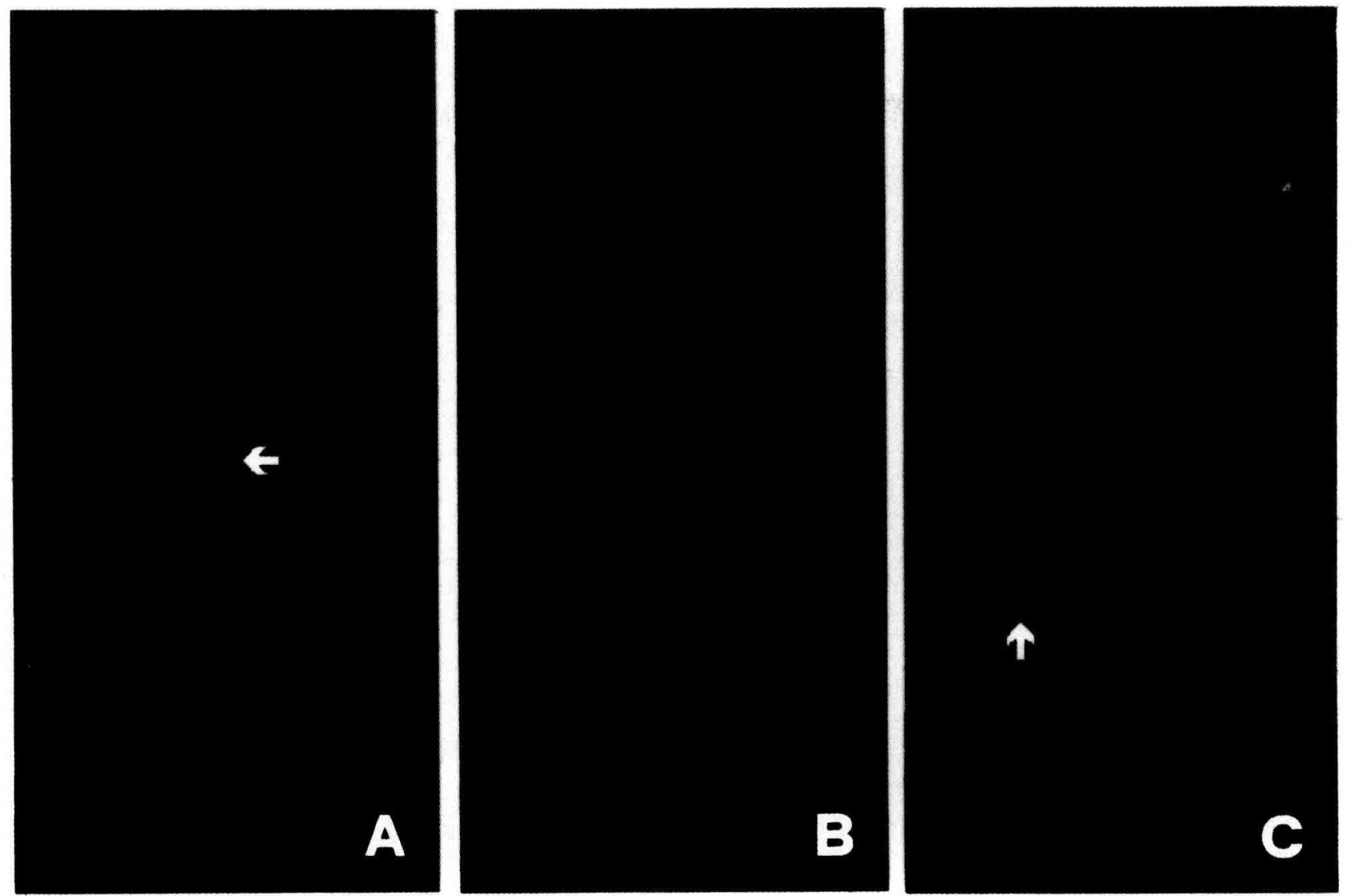

Fig 3. Fluorescence in situ hybridization with the pAs1 probe (red signals) of normal chromosomes $1 \mathrm{D}(\mathbf{A})$ and $1 \mathrm{~A}(\mathbf{B})$ as well as of their $1 \mathrm{AS} .1 \mathrm{AL} / 1 \mathrm{DL}$ exchange product present in the ' $5+10^{\prime} \mathrm{E} 11$ recombinant line $(\mathbf{C})$. Arrows indicate the approximate location of the $1 \mathrm{AL} / 1 \mathrm{DL}$ breakage point.

$1.92 \pm 0.13 \mathrm{seeds} / \mathrm{spikelet}$, respectively) to that of Glu-DI- segregants $(1.87 \pm 0.30)$ of the same F2 progeny, from which ten representatives/genotype were sampled.

\section{DISCUSSION}

Recent results, based on the comparative analysis of the technological properties of the complete set of D-genome substitutions into durum wheat, showed that chromosome 1D contributes signifi- cantly to the improvement of dough quality (Liu et al, 1994a, b, 1995). In particular, replacement by chromosome $1 \mathrm{D}$ of $1 \mathrm{~A}$ compared to that of $1 \mathrm{~B}$, had a much larger effect on rheological parameters, confirming that in tetraploids chromosome $1 \mathrm{~B}$ has a more significant role in quality than $1 \mathrm{~A}$ (Liu et al, 1995). The observed positive effect of chromosome 1D was most probably due to the major storage protein genes, Glu-Dl and GliDI/Glu-D3, located separately on each of the 1D arms. However, the precise role of the separate gene products in the determination of rheological

Table I. F2 segregation in durum wheat of the 1AS.1AL/1DL chromosome carrying the Glu-D $1 d$ allele.

\begin{tabular}{|c|c|c|c|c|c|c|}
\hline \multirow{2}{*}{$\begin{array}{l}\text { Method } \\
\text { of analysis }\end{array}$} & \multirow{2}{*}{$\begin{array}{l}\text { Plants } \\
\text { tested }\end{array}$} & \multicolumn{3}{|c|}{ Glu-D1 ${ }^{+}$} & \multirow[t]{2}{*}{ Glu-D1- } & \multirow[t]{2}{*}{$\chi^{2}$} \\
\hline & & Total & Homoz & Heter & & \\
\hline SDS-PAGE & 109 & 74 & & & 35 & $2.93 \mathrm{~ns}$ \\
\hline FISH & $\begin{array}{c}42 \\
\left(G l u-D 1^{+}\right)\end{array}$ & & 14 & 28 & & 0 \\
\hline
\end{tabular}


properties of durum wheat could not be clearly established with the materials available.

The above reported evidence, coupled with the fact that durum wheat usually lacks functional Glu-Al genes (Branlard et al, 1989) and, of course, Glu-DI genes, is in agreement with the considerations that motivated our chromosome engineering work. We reasoned, in fact, that the introduction into $1 \mathrm{AL}$ of durum wheat of the best Glu-Dl allele, ie, Glu-Dld, coding for the ' $5+10$ ' subunits, could have a major impact on dough quality.

The Glu-Dld recombinant described here represents a suitable material to test this expectation, since, similarly to the Gli-Dl/Glu-D3 recombinants obtained earlier (Ceoloni et al, 1996), the durum wheat chromosome involved in the exchange with the 1D donor chromosome is $1 \mathrm{~A}$. As a matter of fact, 1A-1D preferential pairing has been reported in several instances, and pairing between $1 \mathrm{AL}$ and $1 \mathrm{DL}$, in particular, appears the most frequently occurring between wheat homoeologous arms under phl permissive conditions (Naranjo et al, 1988).

While detailed genetic and physical mapping of the translocation breakpoints in both the 1AL/1DL (Glu-Dld) and 1AS/1DS (Gli-Dl/Glu-D3) recombined chromosomes is yet to be completed, various possibilities for further improving durum wheat quality are currently being tested. One line of work concerns the combination into a Glu-Dld tetraploid carrier of positive alleles at $G l u-3$ and Glu-l loci on chromosome 1B (eg, LMW-2 type and ' $7+8$ ' HMW subunits, respectively). In addition, crosses between the $1 \mathrm{AL} / 1 \mathrm{DL}$ and $1 \mathrm{AS} / 1 \mathrm{DS}$ recombinants are being performed to obtain a double recombined $1 \mathrm{~A}$ chromosome and thus compare the impact of the combined and separate effects of Gli-DI/Glu-D3 and Glu-D1 genes on pasta and bread making quality parameters. Finally, the possibility of using both recombinants, either separate or combined, in both triticale and common wheat breeding is being considered, although, as far as common wheat is concerned, the highly probable terminal location of both 1DS and 1DL transferred segments, which seems to be confirmed by ongoing mapping analyses, might cause multivalent pairing and consequent genotype instability.

Aknowledgements: Financial support to C Ceoloni from CNR (National Council of Research), research contract 95.0.002.CT06, is gratefully acknowledged. The authors thank BS Gill for gift of the pAs1 clone.

\section{REFERENCES}

Autran JC, Feillet P (1985) Genetic and technological basis of protein quality for durum wheat in pasta. Proc Protein Evaluation in Cereals and Legumes, Thessaloniki, Commission of the European Communities, Report EUR 10404 EN, 59-71

Benedettelli S, Margiotta B, Porceddu E, Ciaffi M, Lafiandra D (1992) Effects of the lack of proteins controlled by genes at $G l i-D 1 / G l u-D 3$ loci on breadmaking quality of wheat. J Cereal Sci 16, 69-79

Bozzini A (1988) Origin, distribution and production of durum wheat in the world. In: Durum Wheat: Chemistry and Technology (G Fabriani, C Lintas, eds), AACC, St Paul, MN, USA, 1-16

Branlard G, Autran JC, Monneveux P (1989) Highmolecular weight glutenin subunit in durum wheat (T durum). Theor Appl Genet 78, 353-358

Ceoloni C, Ercoli L, Donini P, Bitti A (1992) Manipulations of the pairing control system of common wheat and alien gene transfer projects. In: EWAC Newsletter 1992 (N Jouve, AJ Worland, eds), 58-63

Ceoloni C, Ciaffi M, Lafiandra D, Giorgi B (1995) Chromosome engineering as a means of transferring 1D storage protein genes from common to durum wheat. Proc 8th Int Wheat Genet Symp, Beijing, China (ZS Li, ZY Xin, eds), 159-163

Ceoloni C, Biagetti M, Ciaffi M, Forte P, Pasquini M (1996) Wheat chromosome engineering at the $4 x$ level: the potential of different alien gene transfers into durum wheat. Euphytica 89, 87-97

Ciaffi M, Lafiandra D, Porceddu E, Benedettelli S (1993) Storage-protein variation in wild emmer wheat (Triticum turgidum ssp. dicoccoides) from Jordan and Turkey. I. Electrophoretic characterization of genotypes. Theor Appl Genet 86, 474-480

Cuadrado A, Vitellozzi F, Jouve N, Ceoloni C (1997) Fluorescence in situ hybridization with multiple repeated DNA probes applied to the analysis of wheat/rye chromosome pairing. Theor Appl Genet 94, 347-355

Gale MD, Miller TE (1987) The introduction of alien genetic variation into wheat. In: Wheat Breeding Its Scientific Basis (FGH Lupton, ed), Chapman and Hall, London, 173-210

Giorgi B (1978) A homoeologous pairing mutant isolated in Triticum durum cv Cappelli. Mutation Breeding Newsletter 11, 4-5

Gupta RB, Paul JG, Cornish GB, Palmer GA, Bekes F, Rathjen AJ (1994) Allelic variation at glutenin subunit and gliadin loci, Glu-1, Glu-3 and Gli-1, of common wheats. I. Additive and interaction effects on dough properties. J Cereal Sci 19, 9-17

Josephides CM, Joppa LR, Youngs VL (1987) Effect of chromosome $1 \mathrm{~B}$ on gluten strength and other characteristics of durum wheat. Crop Sci 27, 212-216 
Khan K, Hamada AS, Patek J (1985) Polyacrilamidegel-electrophoresis for wheat variety identification: effect of variables on gel properties. Cereal Chem $62,310-313$

Lafiandra D, Ciaffi M, Colaprico G, Margiotta B (1993) Comparative effect of null lines at the Glu$D I$ and Glu-D3 loci on wheat qualitative properties. Proc 5th Int Workshop of Gluten Proteins, Detmold, Germany, 255-261

Lawrence GJ, MacRitchie F, Wrigley CW (1988) Dough and baking quality of wheat lines deficient in glutenin subunits controlled by the Glu-Al, Glu-Bl and Glu-DI loci. J Cereal Sci 7, 109-112

Liu CY, Shepherd KW, Gras PW (1994a) Grain yield and quality characteristics of chromosome ID and 1B substitution lines in durum wheat and their F2derived progeny lines. I. Comparisons among the tetraploid phenotypes. J Cereal Sci 20, 23-32

Liu CY, Shepherd KW, Gras PW (1994b) Grain yield and quality characteristics of chromosome $1 \mathrm{D}$ and $1 \mathrm{~B}$ substitution lines in durum wheat and their F2derived progeny lines. II. Preliminary comparisons with normal durum and bread wheats. $J$ Cereal Sci $20,227-234$

Liu CY, Rathjen AJ, Shepherd KW, Gras PW, Giles LC (1995) Grain quality and yield characteristics of D-genome disomic substitution lines in 'Langdon' (Triticum turgidum var. durum). Plant Breeding 114, 34-39

Lukaszewski AJ, Curtis CA (1992) Transfer of the GluDl gene from chromosome 1D of breadwheat to chromosome $1 \mathrm{R}$ in hexaploid triticale. Plant Breeding 109, 203-210
Lukaszewski AJ, Curtis CA (1994) Transfer of the GluDl gene from chromosome 1D to chromosome $1 \mathrm{~A}$ in hexaploid triticale. Plant Breeding 112, 177-182

Mukai Y, Nakahara Y, Yamamoto M (1993) Simultaneous discrimination of the three genomes in hexaploid wheat by multicolor fluorescence in situ hybridization using total genomic and highly repeated DNA probes. Genome 36, 489-494

Naranjo T, Roca A, Giráldez R, Goicoechea PG (1988) Chromosome pairing in hybrids of phlb mutant wheat with rye. Genome $30,639-646$

Payne PI, Holt LM, Jacksonn EA, Law CN (1984) Wheat storage proteins: their genetics and their potential for manipulation by plant breeding. Phil Trans $R$ Soc Lond 304, 359-371

Payne PI, Nightingale MA, Krattiger AF, Holt LM (1987) The relationship between HMW glutenin subunit composition and the bread-making quality of British-grown wheat varieties. I Sci Food Agric $40,51-65$

Pogna NE, Autran JC, Mellini G, Lafiandra D, Feillet P (1990) Chromosome 1B-encoded gliadins and glutenin subunits in durum wheat: genetics and relationship to gluten strength. J Cereal Sci 11, 15-34

Rayburn AL, Gill BS (1986) Isolation of a D-genome specific repeated DNA sequence from Aegilops squarrosa. Plant Mol Biol Rep 4, 102-109

Rogers WJ, Rickatson JM, Sayers EJ, Law CN (1990) Dosage effects of chromosomes of homoeologous group 1 and 6 upon bread-making quality in hexaploid wheat. Theor Appl Genet 80, 281-287

Turchetta T, Ciaffi M, Porceddu E, Lafiandra D (1995) Relationship between electrophoretic pattern of storage proteins and gluten strength in durum wheat landraces from Turkey. Plant Breeding 144, 406-412 